\title{
Atitudes de estudantes universitários frente ao consumo de materiais pornográficos ${ }^{1}$
}

\author{
Valeschka Martins Guerra \\ Fernando Cezar B. de Andrade \\ Mardonio Rique Dias \\ Universidade Federal da Paraíba
}

\begin{abstract}
Resumo
A expansão do mercado de produtos pornográficos traz à tona a discussão acerca da influência dos valores transmitidos pela mídia no comportamento dos indivíduos. A questão da pornografia permanece sem o devido aprofundamento, pois o Brasil ainda é carente de pesquisas nesta área. Este estudo descreve a elaboração e validação de um instrumento de medida das atitudes frente ao consumo de materiais pornográficos, aplicada a 336 universitários e os dados submetidos à análise fatorial. Os 33 itens construídos confirmaram a existência de duas dimensões, que apresentam níveis de precisão adequados: a primeira, denominada "Efeitos positivos da pornografia", em que a expressão do sexo neste tipo de material é tida como favorável à vida sexual $(\alpha=0,94)$; na segunda dimensão, "Efeitos nocivos da pornografia", esta expressão é percebida como prejudicial aos relacionamentos íntimos, associada ao vício e ao isolamento $(\alpha=0,85)$.
\end{abstract}

Palavras-chave: atitudes; pornografia; consumo

\begin{abstract}
University students' attitudes towards pornographic material consumption. The expansion of the pornographic material market raises the question of the influence of the values transmitted by the media in people's behavior. Despite the apparent interest in sexuality by the society in general, Brazil lacks studies on this topic, which has not yet been deeply discussed. This study describes the elaboration and validation of a psychometric instrument for the measuring of attitudes towards the consumption of pornographic material, answered by 336 university students and submitted to a factor analysis. 33 items were built in order to cover two dimensions, presenting adequate reliability scores: (1) "Positive effects of pornography", expressing the idea that pornographic material is favorable to sexual life $(\alpha=0.94)$ and (2) "Harmful effects of pornography", which expresses the idea that this same material is noxious to intimate relationships and it is associated to vice and isolation $(\alpha=0.85)$.
\end{abstract}

Keywords: attitudes; pornography; consumption

A través do estudo da Psicologia, sabemos que as atitudes desempenham funções importantes e específicas para os indivíduos. Elas ajudam a ordenar o ambiente de forma coerente para a compreensão. Desta forma, a pesquisa das atitudes de uma pessoa com relação à sexualidade e sua expressão na sociedade é de fundamental importância, pois, segundo Pasquali, Souza e Tanizaki (1985), as atitudes estão relacionadas ao comportamento que é dirigido a si e aos outros.

Com todo o espaço que a sexualidade em geral tem ocupado na mídia, surgem inúmeros questionamentos acerca da influência que os materiais oriundos do mercado pornográfico podem exercer em crianças, adolescentes e adultos. Essa influência, usualmente vista pelo lado negativo e tida como algo característico da pornografia, seria expressa em atitudes e comportamentos socialmente indesejados, como a busca do sexo pelo sexo, comportamentos sexistas e agressivos, além de parafilias e toda uma gama de crimes sexuais. O Brasil, no entanto, ainda carece de pesquisas sobre o tema, que se apresenta como um dos mais problemáticos para estudo, pois o termo pornografia é difícil de ser definido e, conseqüentemente, torna-se igualmente difícil medi-lo.

\section{Conceituação de pornografia e estudos prévios}

Várias definições de pornografia já foram formuladas, por inúmeros estudiosos. No entanto, a definição deste termo e as crenças associadas a ele são construídas histórica e culturalmente, além de serem perpassadas pelos filtros morais, pelos valores intrínsecos ao indivíduo e, conseqüentemente, suas ideologias. 
A definição mais aceita atualmente e utilizada neste estudo é a de que pornografia é uma representação do comportamento erótico em livros, imagens, filmes, etc., com a intenção de causar excitação sexual (Encyclopaedia Britannica, 1999).

Reportando-nos à literatura especializada, são encontrados trabalhos como a pesquisa realizada nos Estados Unidos por Alfred Kinsey, em 1953. Ele obteve dados que afirmavam que $47 \%$ das mulheres e $36 \%$ dos homens apresentam resposta erótica aos filmes sensuais, $60 \%$ das mulheres e $59 \%$ dos homens apresentam resposta erótica à leitura de literatura erótica; $32 \%$ das mulheres e $77 \%$ dos homens se sentiram estimulados com gravuras ou desenhos de atividade sexual; $14 \%$ das mulheres e $47 \%$ dos homens se sentiram estimulados ouvindo histórias eróticas (citado por Suplicy, 1999).

Uma outra pesquisa da mesma época, realizada pela revista Psychology Today com uma amostra de 20.000 leitores, perguntou se estes já haviam utilizado material pornográfico para se excitar: $92 \%$ dos homens e $72 \%$ das mulheres que responderam disseram que sim (citado por Suplicy, 1999).

Com todos esses números, a pornografia pode ser encarada como a transformação do sexo em mercadoria. Sabemos que "a sexualidade gera prazer, e o prazer, ou pelo menos a sua promessa, proporciona um incentivo para os produtos comercializados em uma sociedade capitalista" (Giddens, 1993, p. 194). Esta visão da situação explicaria o porquê de tantas imagens relacionadas à sexualidade que surgem na mídia todos os dias. Essa valorização do sexo e, conseqüentemente, do corpo, conduz a uma busca incessante por aperfeiçoamentos físicos e biológicos que levem a um aumento de prazer.

A busca pelo corpo perfeito tem como característica principal a exposição deste enquanto código visual dos valores transmitidos pela mídia e demais meios de comunicação. $\mathrm{O}$ corpo torna-se um objeto que pode, ou melhor, deve ser exposto à vista de todos. E, quanto mais se mostra, maior a tolerância da sociedade com relação à pornografia, pois já existe uma cultura de exposição e exaltação do corpo e do sexo enquanto fornecedores de prazer e contato.

No entanto, para Giddens (1993), essa visão da pornografia como transformação do sexo em um produto a ser comercializado, impulsionando uma importante fatia do mercado financeiro, é uma visão parcial, pois não explica o porquê da sexualidade ter a importância que tem.

Várias teorias procuraram compreender este fenômeno e seus efeitos sobre os indivíduos. Uma destas teorias, baseando-se em certos pressupostos conceituais psicanalíticos, propõe que a pornografia pode ser benéfica, servindo como uma válvula de escape, ou de catarse para indivíduos potencialmente agressivos e/ou com conduta sexual desviante.

Uma outra teoria, ligada ao desenvolvimento cognitivo, afirma que a exposição prolongada a estes estímulos pode levar a mudanças cognitivas nos observadores, que irão afetar suas atitudes e comportamentos, pois aqueles temas ou conceitos que foram ativados recentemente, estando mais acessíveis cognitivamente, serão usados para organizar as informações e guiar os julgamentos e as ações do indivíduo. Ou seja, se a pornografia consumida é associada à violência e essa experiência for considerada prazerosa para o sujeito, ele irá basear suas atitudes e comportamentos nos conceitos que foram apreendidos do material observado (Genuis, Violato, \& Paolucci, 1998).

Estes dados nos mostram uma relação entre a utilização de materiais pornográficos e determinadas atitudes consideradas anteriores a comportamentos agressivos. No entanto, uma pesquisa realizada anos antes por Kutchinsky (1973), acerca da legalização de materiais pornográficos na Dinamarca, mostrou que a relação entre pornografia e crimes sexuais não é direta. Após a liberação deste tipo de material no país, houve um decréscimo significativo do número de crimes sexuais registrados pela polícia. Este resultado não comprova que houve necessariamente uma diminuição real da incidência de estupros e abusos sexuais, pois as vítimas podem simplesmente não ter registrado a ocorrência. Contudo, os dados mostram que o número de crimes não aumentou, o que já é bastante significativo.

Outros autores (Gray, 1982) afirmam que existem poucas evidências de que a exposição à pornografia produz comportamentos agressivos em homens. No entanto, este tipo de material leva a um aumento nos níveis de agressividade em homens considerados violentos. Os autores concluem que a agressividade é um problema social maior do que a pornografia, particularmente em homens que são incapazes de distingui-la do impulso sexual e do controle sobre as mulheres.

Um estudo de Zillman e Bryant (1982) mostrou que a exposição à pornografia diminui a satisfação dos sujeitos com: (1) seus atuais relacionamentos; (2) a aparência física de seus parceiros; (3) o afeto e o comportamento sexual do parceiro e (4) a importância da confiança no relacionamento. Além disso, há um aumento na importância do sexo sem necessidade de um envolvimento emocional.

A partir da década de 1990, surgiram mais estudos sobre as atitudes e opiniões dos sujeitos a respeito do consumo de materiais de sexo explícito. Os resultados dessas pesquisas mostram que homens e mulheres concordam com a proteção legal da publicação deste tipo de material, em defesa da liberdade de expressão. Também foi encontrado que os homens percebem mais efeitos positivos na utilização de pornografia para si mesmos e para os outros, mas que ambos os sexos concordam que a pornografia pode ter tanto efeitos positivos quanto efeitos negativos sobre os indivíduos (Lottes, Weinberg, \& Weller, 1993; Thompson, Chaffee, \& Oshagan, 1990).

A visão de que este tipo de material pode ter diversos efeitos sobre as pessoas é compartilhada por outros pesquisadores. Thornton (1986) critica esta visão de que a pornografia é prejudicial e constitui uma séria afronta moral às mulheres. Ele conclui que a pornografia é, na verdade, um alvo fácil, pois o problema é o sexismo presente em nossa cultura. Uma proibição legal da pornografia impediria a liberdade de outros grupos, inclusive das próprias feministas. Donnerstein e Linz (1986), afirmam que o problema mais importante na mídia não é a apresentação de relações sexuais de forma explícita, mas sim a violência associada ao sexo; Eysenck (1976) 
acredita que a questão está na associação do sexo com emoções que nem sempre são desejáveis, como agressividade, hostilidade, crueldade, medo, ansiedade e desprezo.

Essa associação é, sem dúvida, preocupante devido à influência sobre as atitudes das pessoas frente a situações que envolvam a sexualidade. Essas atitudes são o resultado das crenças positivas e negativas que são aprendidas ao longo da vida e possuem um certo grau de associação com os comportamentos posteriores do indivíduo.

Krüger (1986) afirma que as crenças são pequenas "teorias" que criamos, com a finalidade de afirmar ou negar uma relação entre um objeto e algum atributo que este possa vir a ter. Assim, as crenças são produtos psicológicos que se originam a partir de processos cognitivos. Elas têm a função de dar significado aos objetos que nos cercam, organizando o ambiente de forma a fazer com que este se torne compreensível para o indivíduo. "Psicologicamente, o que mais importa a uma pessoa, influenciando decisivamente seu comportamento, não é a realidade como tal, mas como ela supõe ou imagina que esta seja" (Krüger, 1986, p. 32).

As atitudes são formadas a partir das experiências dos indivíduos com o ambiente. Assim, quando as experiências pessoais são significativas, tendem a criar crenças ou fortalecer aquelas já existentes. Middlebrook (1980) sugere que a ausência total de experiências de qualquer tipo com um determinado objeto, também ajuda na formação de atitudes, especificamente, negativas.

Além das experiências, o contexto cultural em si, com seu sistema de crenças compartilhadas, que constituem as normas sociais, seus valores e expectativas relativas à forma correta de comportamento frente a determinadas situações, também formam nossas atitudes, juntamente com as influências de pais, amigos, instituições como escola e igreja e os meios de comunicação de massa.

Assim, para Anastasi e Urbina (2000, p. 333), atitude é uma "tendência a reagir favorável ou desfavoravelmente a uma classe designada de estímulos". Esta definição também é aceita por autores como Middlebrook (1980), que acrescenta que essa disposição guia, além do comportamento, os pensamentos e sentimentos do indivíduo frente ao objeto em questão; e Krüger (1986), que afirma ainda que, vista deste modo, "torna-se incoerente falar em atitude neutra, ou em atitude quando não houver um mínimo de mobilização afetiva” (p. 34).

Por isso, torna-se tão importante seu estudo, o que nos levou a elaborar um instrumento com tais propósitos.

\section{Método}

Para a análise posterior dos dados desta pesquisa, foi definida uma hipótese principal, que afirmava que as atitudes dos consumidores iriam diferir das atitudes dos não-consumidores de materiais pornográficos. Com esta hipótese prédefinida, iniciou-se a pesquisa de campo, dividida em duas etapas, a saber: na primeira etapa, foi realizado um levantamento das crenças acerca do tema, para a construção do instrumento, cuja construção, aplicação e validação se deu na segunda etapa.

\section{Etapa I - Levantamento das crenças}

\section{Amostra}

Participaram da primeira etapa da pesquisa 34 indivíduos, adultos, estudantes universitários, sendo 22 de universidade pública e 12 de universidade particular. Quanto ao gênero, a amostra dividiu-se em 18 do sexo feminino (53\%), com idade variando entre 18 e 25 anos (média de 20,4 anos, $D P=$ $2,50)$ e 16 do sexo masculino (47\%), cuja variação de idade foi de 18 a 25 anos (média de 22,4 anos, $D P=2,70$ ).

\section{Instrumento}

Foi organizado um roteiro de entrevista com a finalidade de levantar as crenças relativas ao consumo de materiais pornográficos, solicitando aos participantes que informassem as vantagens e desvantagens deste consumo, além de algumas questões sócio-demográficas.

\section{Procedimentos}

Para a realização das entrevistas, os sujeitos foram contatados em suas universidades. Foi pedida a colaboração e todos eles tiveram a liberdade de responder ou não às questões. Para que não houvesse identificação do sujeito, os resultados das entrevistas foram colocados juntos em um envelope. Em média, 10 minutos foram suficientes para responder às questões.

\section{Análise dos dados}

Os dados resultantes dessas entrevistas foram divididos em categorias com a ajuda de dois juízes, professores da Universidade Federal da Paraíba, especialistas em sexualidade.

Das crenças negativas, $81,4 \%$ foram agrupadas em categorias, enquanto $18,6 \%$ foram descartadas, por serem consideradas idiossincráticas. As categorias extraídas foram: Banalização do sexo (27,85\%), Má formação sobre o sexo (21, $5 \%)$, Prejuízos a relacionamentos $(20,25 \%)$, Alienação ou isolamento (19\%) e Vício $(11,4 \%)$.

Do total de crenças positivas, $80,6 \%$ foram mantidas e $9,4 \%$ foram descartadas. As categorias de similaridade que agruparam as crenças foram: Obtenção de informações (24\%), Melhorar a relação com o parceiro (24\%), Aumento do prazer (22\%), Aumento das fantasias (16\%) e Satisfação (14\%).

Após a realização deste levantamento, passamos à etapa seguinte da pesquisa.

\section{Etapa II - Construção, aplicação e validação do instrumento}

\section{Validade semântica}

A partir das crenças emitidas na etapa anterior da pesquisa, foi elaborado um único instrumento geral, com 40 itens. Este instrumento foi aplicado, como piloto, a 20 estudantes universitários de instituições públicas e privadas, de ambos os sexos, a fim de verificar o nível de clareza e compreensão das questões.

Após as devidas correções, foi realizada a aplicação final do instrumento. 


\section{Amostra}

Participaram do estudo 336 estudantes universitários, com idade variando de 17 a 52 anos (média $=23,4 ; D P=5,96$ ), de ambos os sexos, sendo $51 \%$ do sexo feminino (média de idade $=24,2 ; D P=6,13$ ) e $49 \%$ do sexo masculino (média de idade $=22,5 ; D P=5,65)$. Os participantes apresentaram-se, em sua maioria, como católicos (61\%), evangélicos $(16,7 \%)$ ou sem religião $(21 \%)$. Os solteiros constituíam $82 \%$ da amostra, enquanto os casados representavam $17 \%$ e os separados, divorciados ou viúvos sendo o $1 \%$ restante.

\section{Instrumento}

O instrumento é constituído de três partes distintas: um questionário para levantar o perfil dos usuários de materiais pornográficos, uma escala de diferencial semântico, para verificar as crenças normativas com relação ao uso de pornografia e uma escala de atitude frente ao consumo deste tipo de material.

No questionário inicial, solicitavam-se as informações referentes aos dados demográficos, como sexo, idade, religião, etc. Além dessas informações, o questionário ainda continha perguntas acerca do consumo e/ou contato com materiais pornográficos, como a idade do primeiro contato e o tipo de material utilizado, se é usuário atualmente, de que tipo de material, freqüência e finalidade do uso.

A segunda parte era constituída de uma escala de diferencial semântico, contendo três conjuntos de adjetivos, variando em 5 pontos: benéfico - nocivo; agradável - desagradável; prudente - imprudente. Essa escala foi desenvolvida de acordo com a teoria de Osgood, de mensuração das atitudes (Baron, Byrne, \& Griffitt, 1974; Pasquali, 1999).

A Escala de Atitudes Frente ao Consumo de Pornografia, composta de 25 questões, derivou da análise de conteúdo das respostas dos estudantes nas entrevistas realizadas na etapa anterior da pesquisa. Os itens são acompanhados de escalas de 5 pontos, onde 1 significa discordo totalmente e 5 , concordo totalmente.

\section{Procedimentos}

Para aplicação dos questionários e coleta dos dados, os sujeitos foram contatados em seus locais de estudo e foi pedida a colaboração de todos, nos mesmos moldes da aplicação das entrevistas, sendo aplicados coletivamente em sala de aula. Uma vez solicitada a colaboração voluntária dos participantes, foi informado a estes que este estudo procurava conhecer suas atitudes e opiniões a respeito do tema, sendo-lhes garantida a confidencialidade das respostas. Para que não houvesse identificação do sujeito, os questionários respondidos eram colocados juntos em um envelope. Uma média de 20 minutos foi suficiente para responder aos questionários.

\section{Apuração dos resultados}

Os dados resultantes da aplicação foram inseridos no computador para as análises estatísticas das variáveis através do programa SPSS 9.0 for Windows (Pacote Estatístico para Ciências Sociais Versão 9.0 para Windows).
Foram realizadas análises de validade, fidedignidade e fatorabilidade da escala, além do levantamento dos resultados de freqüências e escores individuais de atitudes dos participantes.

\section{Resultados e Discussão}

\section{Perfil do consumidor e do não consumidor}

A seção referente ao perfil do consumidor é constituída por dados relativos ao contato com materiais pornográficos. As respostas a estas questões foram agrupadas por gênero, devido ao fato de que inúmeras pesquisas acerca do uso de materiais pornográficos apresentam diferenças significativas com relação a esta variável, demonstrando esta ser uma análise importante.

O primeiro quesito desta parte específica do instrumento perguntava se o sujeito já havia tido algum contato, no passado, com esse tipo de material. Do total da amostra, 97,6\% dos homens e $71,3 \%$ das mulheres afirmam já ter entrado em contato com algum tipo de material pornográfico, enquanto $2,4 \%$ do grupo masculino e $28,1 \%$ do feminino afirmam o contrário (qui-quadrado $=42,54 ; p<0,001$ ).

$\mathrm{Na}$ questão que procurava investigar o consumo atual de material pornográfico por parte dos participantes da amostra, foram obtidos os seguintes resultados: do número total de sujeitos na amostra $(N=336)$, apenas $39 \%$ dos sujeitos, de ambos os sexos, afirmaram consumir materiais pornográficos, enquanto $61 \%$ afirmaram o contrário (qui-quadrado $=$ $71,0 ; p<0,001)$. O grupo de não consumidores é formado, basicamente, de mulheres (69\%) com média de idade igual a 24,2 anos $(D P=6,12)$. Os homens correspondem a $31 \%$, com média de idade de 23,3 anos $(D P=7,78)$. Do total de consumidores, $77,8 \%$ pertencem ao sexo masculino (média de idade $=$ 22 anos; $D P=3,73$ ) e $22,2 \%$ ao sexo feminino (média de idade $=24,2$ anos; $D P=6,28)$. A média de idade geral é de 22,5 anos $(D P=4,49)$.

Entre os consumidores os materiais mais freqüentemente utilizados pelos homens foram: as revistas $(76,5 \%)$, os sites da Internet $(67,6 \%)$ e os filmes $(56 \%)$. Para as mulheres, os materiais mais consumidos são as revistas $(65,5 \%)$, os filmes $(55,2 \%)$ e os sites da Internet $(44,8 \%)$. Esses dados reafirmam os resultados encontrados por Kinsey (citado por Suplicy, 1999).

Um dado interessante de ser observado nessas respostas é o fato da elevada utilização de sites da Internet como fontes de contato com a pornografia. Esses dados correspondem às atuais pesquisas sobre o assunto (Super Interessante, 1999), que mostram como a atual tecnologia é utilizada por adolescentes e adultos para a busca do sexo e do prazer.

A última questão da seção relativa ao perfil do consumidor de pornografia dizia respeito à finalidade da utilização do material pornográfico. As opções deste quesito de múltipla escolha foram retiradas das crenças positivas recolhidas na primeira etapa da pesquisa. Os resultados podem ser observados de forma detalhada na Tabela 1 . 
Tabela 1

Utilidade dos materiais pornográficos

\begin{tabular}{lrr}
\hline \multicolumn{3}{c}{$\begin{array}{c}\text { Com que finalidade você utiliza materiais pornográficos? } \\
\text { (Marque quantas alternativas forem necessárias) }\end{array}$} \\
\hline \multicolumn{1}{c}{ Respostas } & Masculino & Feminino \\
\hline Ter mais satisfação sexual & $37,2 \%$ & $13,8 \%$ \\
Obter prazer & $39,0 \%$ & $13,8 \%$ \\
Melhorar a relação sexual com o(a) parceiro(a) & $32,3 \%$ & $27,6 \%$ \\
Ter mais fantasias sexuais & $50,0 \%$ & $41,4 \%$ \\
Procurar novas posições e técnicas sexuais para sair da & $37,2 \%$ & $24,1 \%$ \\
rotina & $55,8 \%$ & $72,4 \%$ \\
Obter informações reais sobre sexualidade & $11,7 \%$ & $17,2 \%$ \\
Outros & & \\
\hline
\end{tabular}

Os participantes masculinos da amostra afirmaram que utilizam esse tipo de material com duas grandes finalidades: "Obter informações reais sobre sexualidade", com 55,8\% de respostas afirmativas, e "Ter mais fantasias sexuais", correspondendo a $50 \%$ da amostra. Essas duas opções concentram o maior número de respostas. No entanto, as outras opções também obtiveram um número expressivo de respostas positivas, ficando em torno dos $30 \%$.

Com relação à amostra feminina, a maioria das mulheres $(72,4 \%)$ afirmou que procura materiais pornográficos para "Obter informações reais sobre sexualidade" e, em seguida, "Ter mais fantasias sexuais" $(41,4 \%)$.

Os dados apresentados mostram que os consumidores desse material são, em sua maioria, homens solteiros, em torno dos 22 anos de idade, católicos não-praticantes, que utilizam revistas, sites da internet e filmes de forma regular com o objetivo de obter informações sobre sexualidade e ter mais fantasias sexuais.

\section{Escala de diferencial semântico}

A escala de diferencial semântico foi introduzida neste instrumento com o objetivo de confirmar as atitudes expressas pelos participantes na escala principal, cujos resultados serão apresentados e comparados posteriormente. Os três itens constituintes desta escala são compostos dos seguintes pares de adjetivos: Benéfico versus Nocivo; Agradável versus Desagradável; e Prudente versus Imprudente.

Aos sujeitos foi solicitado que marcassem, na escala de 5 pontos apresentada, o valor mais aproximado do adjetivo que melhor expressasse suas opiniões acerca do uso de materiais pornográficos, sendo que quanto maior o valor (mais próximo de 5), mais benéfico, agradável ou prudente é a sua utilização.

Os itens foram submetidos, inicialmente, a uma análise fatorial, através do método dos componentes principais, com o objetivo de verificar a possibilidade de uma fatoração. Como resultado, emergiu um fator que explica $81 \%$ da variância total. Posteriormente, os itens foram submetidos a uma segunda análise fatorial (Principal Axis Factoring), que reafirmou a existência de um único fator com condições favoráveis para a análise fatorial (Kayser Meier Olkin =0,746; Teste de Esfericidade de Bartlett $=563,021 ; p<0,001)$, e explicando, por sua vez, $72,6 \%$ da variância.

A Tabela 2 apresenta os resultados das análises efetuadas com esta escala. Como podemos perceber, este fator obteve um adequado índice de fidedignidade (Alpha de Cronbach = $0,88)$, comprovando a confiabilidade dos itens.

Os resultados das análises realizadas para avaliar as atitudes dos sujeitos estão apresentados na Tabela 3.

Tabela 2

Cargas fatoriais, eigenvalue, percentual de variância $e$ índice de fidedignidade da escala de diferencial semântico

\begin{tabular}{|c|c|c|}
\hline \multicolumn{3}{|c|}{ 15. O uso de materiais pornográficos é: } \\
\hline Itens* & Conteúdo & Carga fatorial \\
\hline $\mathrm{C}$ & Prudente versus Imprudente & 0,88 \\
\hline A & Benéfico versus Nocivo & 0,84 \\
\hline B & Agradável versus Desagradável & 0,83 \\
\hline
\end{tabular}

* Os itens foram ordenados segundo a magnitude de suas cargas fatoriais

Tabela 3

Consumidores versus não-consumidores: média, desvio padrão, teste t $e$ nível de significância dos itens da escala de diferencial semântico

\begin{tabular}{l|ccc|c|c|c|c|c}
\hline \multirow{2}{*}{ Itens } & \multicolumn{2}{|c|}{ Consumidor } & \multicolumn{2}{|c|}{ Não-consumidor } & \multirow{2}{*}{$t$} & \multirow{2}{*}{$g l$} & \multirow{2}{*}{$p$} \\
\cline { 2 - 5 } & Média & $D P$ & \multicolumn{1}{c|}{ Média } & DP & & & \\
\hline A & 3,13 & 0,83 & 2,44 & 1,11 & 6,09 & 333 & 0,001 \\
B & 3,70 & 1,00 & 2,53 & 1,31 & 8,60 & 332 & 0,001 \\
C & 3,00 & 0,89 & 2,25 & 1,10 & 6,40 & 333 & 0,001 \\
\hline
\end{tabular}

Nota: Valor de $t$ da escala $=8,544 ; p<0,001$ 
Ao comparamos estas médias com as da amostra de nãoconsumidores, podemos observar uma diferença entre os grupos. Os sujeitos da amostra de consumidores mostram-se favoráveis quanto ao consumo de materiais pornográficos, pois as médias dos itens encontram-se acima do ponto neutro da escala, enquanto que o grupo de não-consumidores situa-se abaixo deste mesmo ponto, demonstrando sua discordância com a questão. Estes dados confirmam a hipótese inicial da diferença de atitudes entre os dois grupos.

\section{Escala de atitudes}

Com o objetivo de realizar uma estimativa do número de dimensões existentes nos itens integrantes do instrumento, foi realizada uma análise fatorial exploratória, através do método dos componentes principais. Esta análise apresentou dois fatores, que explicavam por volta de $51 \%$ da variância total. Em seguida, os itens foram submetidos a uma segunda análise fatorial (PAF), que confirmou a existência destes mesmos fatores $(\mathrm{KMO}=0,925$; Bartlett $=4779,461 ; p<0,001)$, explicando $46,7 \%$ da variância.

A Tabela 4 apresenta os resultados das análises efetuadas com o fator I, denominado aqui de "Efeitos positivos da pornografia". Como podemos perceber, este fator apresentou um adequado índice de fidedignidade (Alpha de Cronbach $=$ 0,94), o que comprova a confiabilidade dos itens.

Os 12 itens que compõem este fator referem-se ao consumo de pornografia como um potente recurso para uma vida sexual mais prazerosa e mais bem informada. Atitudes favoráveis com relação a este fator estão baseadas em crenças positivas de que os materiais pornográficos podem melhorar a relação entre os parceiros, proporcionar satisfação e prazer sexual e aumentar as fantasias dos indivíduos que os utilizam. As respostas dadas pelos sujeitos aos itens deste fator estão expostas na Tabela 5.

Tabela 4

Fator I - Efeitos positivos da pornografia: cargas fatoriais, eigenvalue, percentual de variância e índice de fidedignidade

\begin{tabular}{llr}
\hline Itens* & \multicolumn{1}{c}{ Enunciado } & $\begin{array}{r}\text { Carga } \\
\text { fatorial }\end{array}$ \\
\hline 24 & Eu consumiria materiais pornográficos para aumentar minhas fantasias. & 0,81 \\
38 & Eu utilizaria materiais pornográficos para obter mais satisfação sexual. & 0,76 \\
36 & Eu compraria materiais pornográficos para melhorar minha relação com meu & 0,75 \\
& (minha) parceiro (a). & 0,74 \\
26 & É correto utilizar materiais pornográficos para ter mais fantasias. & 0,72 \\
16 & Eu usaria materiais pornográficos para aumentar o meu prazer sexual. & 0,70 \\
25 & É certo aumentar o prazer recorrendo a pornografia. & 0,70 \\
18 & Comprar materiais pornográficos para obter satisfação sexual é bom. & 0,69 \\
22 & O uso de materiais pornográficos ajuda a obter satisfação sexual. & 0,69 \\
23 & Consumir materiais pornográficos aumenta o prazer. & 0,68 \\
40 & Comprar materiais pornográficos para melhorar a relação com o (a) parceiro (a) & 0,64 \\
31 & é correto. & 0,48 \\
35 & A utilização de materiais pornográficos melhora a relação com o (a) parceiro (a). & \multicolumn{2}{c}{ Alpha de Cronbach 0,94} \\
\hline Eigenvalue 6,58 que utilizam materiais pornográficos têm mais fantasias. & Variância explicada 27,4\% & \multicolumn{2}{c}{ Clicas }
\end{tabular}

* Os itens foram ordenados segundo a magnitude de suas cargas fatoriais

Tabela 5

Efeitos positivos da pornografia: consumidores versus não-consumidores

\begin{tabular}{|c|c|c|c|c|c|c|c|}
\hline \multirow{2}{*}{ Itens } & \multicolumn{2}{|c|}{ Consumidor } & \multicolumn{2}{|c|}{ Não-consumidor } & \multirow{2}{*}{$t$} & \multirow{2}{*}{$g l$} & \multirow{2}{*}{$p$} \\
\hline & Média & $D P$ & Média & $D P$ & & & \\
\hline $24 *$ & 3,35 & 1,22 & 2,44 & 1,45 & 6,185 & 334 & 0,001 \\
\hline $38^{*}$ & 3,26 & 1,15 & 2,36 & 1,33 & 6,603 & 334 & 0,013 \\
\hline $36^{*}$ & 3,15 & 1,12 & 2,47 & 1,39 & 4,892 & 334 & 0,001 \\
\hline $26^{*}$ & 3,36 & 1,01 & 2,57 & 1,26 & 6,323 & 334 & 0,001 \\
\hline 16 & 3,38 & 1,27 & 2,33 & 1,33 & 7,171 & 334 & 0,132 \\
\hline $25^{*}$ & 3,19 & 0,98 & 2,22 & 1,24 & 7,998 & 334 & 0,001 \\
\hline 18 & 3,02 & 1,20 & 2,14 & 1,23 & 6,457 & 334 & 0,690 \\
\hline $22 *$ & 3,55 & 1,03 & 2,62 & 1,19 & 7,576 & 334 & 0,007 \\
\hline $23 *$ & 3,36 & 0,99 & 2,39 & 1,13 & 8,274 & 334 & 0,004 \\
\hline $40^{*}$ & 3,26 & 0,96 & 2,44 & 1,26 & 6,762 & 334 & 0,001 \\
\hline $31^{*}$ & 3,18 & 0,86 & 2,43 & 1,14 & 6,796 & 334 & 0,001 \\
\hline 35 & 3,50 & 0,98 & 3,13 & 1,17 & 3,009 & 334 & 0,400 \\
\hline
\end{tabular}

* Itens com diferenças consideradas significativas. Teste t do fator: $t=8,833 ; p<0,001$ 
A comparação entre as atitudes dos consumidores e nãoconsumidores apresenta-nos uma diferença significativa entre os dois grupos, sendo que o primeiro tem uma atitude mais favorável com relação ao consumo de pornografia. Essas diferenças podem ser observadas mais claramente nos itens $22,23,24,25,26,31,36,38$ e 40.

Sendo assim, o grupo de consumidores de materiais pornográficos concorda que este consumo é benéfico para o aumento de suas fantasias, para a obtenção de satisfação e prazer sexual, além de proporcionar uma melhoria na relação com o(a) parceiro(a).

O segundo fator, denominado "Efeitos nocivos da pornografia", por sua vez, também obteve um alto nível de fidedignidade (Alpha de Cronbach $=0,85$ ), explicando 19,3\% da variância total, como mostra a Tabela 6 . Os itens 17, 28 e 32 foram revertidos, devido às suas características semânticas, corrigindo, assim, suas cargas fatoriais.
Os 12 itens constituintes deste fator expressam uma visão do consumo de pornografia como um comportamento com conotações negativas, para a vida afetiva, sexual e social dos indivíduos. Atitudes favoráveis frente a este fator expressam crenças negativas de que os materiais pornográficos podem prejudicar os relacionamentos íntimos, por estarem associados a vício e isolamento, além de não serem uma fonte apropriada de informações sobre a sexualidade. As respostas dadas pelos sujeitos aos itens deste fator estão expostas na Tabela 7.

Como podemos observar, ao compararmos as médias de respostas da amostra de consumidores com a de não-consumidores, as atitudes dos dois grupos com relação aos efeitos nocivos dos materiais pornográficos diferem de forma significativa, diferenças estas apresentadas nos itens 17, 19, 21, $28,29,30,34,37$ e 39.

Tabela 6

Fator II - Efeitos nocivos da pornografia: cargas fatoriais, eigenvalue, percentual de variância e índice de fidedignidade

\begin{tabular}{clc}
\hline Itens* & \multicolumn{1}{c}{ Enunciado } & $\begin{array}{c}\text { Carga } \\
\text { fatorial }\end{array}$ \\
\hline 34 & A utilização de pornografia é prejudicial, pois vicia. & 0,68 \\
37 & As informações sobre sexualidade, disponíveis nos materiais pornográficos, são & 0,67 \\
& prejudiciais para a formação sexual. & 0,60 \\
30 & Os materiais pornográficos tornam o sexo banal. & 0,59 \\
21 & O uso de materiais pornográficos prejudica a relação com o(a) parceiro(a). & 0,56 \\
19 & O uso de materiais pornográficos prejudica a formação sexual dos indivíduos. & 0,55 \\
39 & O uso de materiais pornográficos pode colocar em risco um relacionamento. & 0,54 \\
33 & A banalização do sexo, causada pelos materiais pornográficos, é ruim. & 0,51 \\
29 & O consumo de materiais pornográficos vicia. & 0,42 \\
$17 * *$ & É certo obter informações sobre sexualidade através de materiais pornográficos. & 0,41 \\
27 & Pessoas que adquirem materiais pornográficos tendem a se isolar das outras & 0,40 \\
$28 * *$ & pessoas. & 0,34 \\
$32 * *$ & Euteriais pornográficos são úteis como fontes de informação sobre sexualidade. & \multicolumn{1}{c}{ Alpha de Cronbach 0,85} \\
\hline Eigenvalue 4,63 & Variância explicada $19,3 \%$ & \\
* Os itens foram ordenados segundo a magnitude de suas cargas fatoriais & \\
** Itens com enunciados revertidos &
\end{tabular}

Tabela 7

Efeitos nocivos da pornografia: consumidores versus não-consumidores

\begin{tabular}{lccccccc}
\hline \multirow{2}{*}{ Itens } & \multicolumn{2}{c}{ Consumidor } & \multicolumn{2}{c}{ Não-consumidor } & \multirow{2}{*}{$t$} & \multirow{2}{*}{$g l$} & \multicolumn{2}{c}{$p$} \\
\cline { 2 - 4 } & Média & $D P$ & Média & $D P$ & & & \\
\hline $34^{*}$ & 2,79 & 1,14 & 3,37 & 1,39 & 4,169 & 334 & 0,001 \\
$37^{*}$ & 2,58 & 1,01 & 3,15 & 1,27 & 4,549 & 334 & 0,036 \\
$30^{*}$ & 2,84 & 1,23 & 3,29 & 1,40 & 3,063 & 333 & 0,006 \\
$21^{*}$ & 2,19 & 0,93 & 2,77 & 1,30 & 4,729 & 334 & 0,001 \\
$19^{*}$ & 2,44 & 0,87 & 2,99 & 1,29 & 4,635 & 334 & 0,001 \\
$39^{*}$ & 2,75 & 1,13 & 3,35 & 1,25 & 4,517 & 334 & 0,037 \\
33 & 3,46 & 1,20 & 3,95 & 1,23 & 3,594 & 334 & 0,582 \\
$29 *$ & 3,13 & 1,26 & 3,51 & 1,37 & 2,653 & 334 & 0,043 \\
$17^{*}$ & 2,79 & 1,01 & 3,58 & 1,31 & 6,209 & 334 & 0,001 \\
27 & 2,27 & 1,08 & 2,82 & 1,28 & 4,181 & 334 & 0,071 \\
$28^{*}$ & 3,26 & 0,98 & 3,70 & 1,25 & 3,461 & 334 & 0,001 \\
32 & 3,20 & 1,20 & 3,72 & 1,34 & 3,595 & 334 & 0,106 \\
\hline
\end{tabular}

* Itens com diferenças consideradas significativas.

** Teste $t$ do fator: $t=7,283 ; p<0,001$ 
Dessa forma, os consumidores discordam da idéia de que a pornografia traga efeitos nocivos como o vício, a banalização do sexo, prejuízos ao relacionamento e a formação sexual, expressando-se de forma contrária aos não-consumidores, que percebem o consumo como prejudicial.

Estes resultados coincidem com os resultados apresentados anteriormente, na análise da escala de diferencial semântico, comprovando assim a veracidade dos dados e a hipótese originalmente formulada de que os consumidores e não consumidores diferem em suas atitudes com relação à pornografia.

\section{Conclusão}

As análises das variáveis inseridas no instrumento ajudaram a traçar o perfil apresentado. $\mathrm{O}$ grupo de consumidores é formado por homens solteiros, com média de idade igual a 22 anos, católicos não-praticantes, que utilizam a pornografia regularmente, com o objetivo de obter informações acerca da sexualidade e ter mais fantasias sexuais. Este grupo percebe o consumo como favorável à sua formação sexual e à obtenção de prazer e satisfação, discordando da associação da pornografia com a banalização do sexo e com o vício.

O grupo não-consumidor é formado, basicamente, de mulheres solteiras, com média de idade igual a 24,2 anos, católicas praticantes que já tiveram algum contato com materiais pornográficos, mas não o utilizam atualmente, percebendo-o como prejudicial.

A partir dos dados encontrados, podemos concluir que a hipótese inicialmente elaborada, de que as atitudes de consumidores e não-consumidores frente ao consumo de pornografia apresentaria uma diferença significativa, foi confirmada.

Os dados apresentados tornaram possível concluir que a Escala de Atitudes Frente à Pornografia apresenta características psicométricas de validade e precisão suficientemente satisfatórias, garantindo-lhe legitimidade enquanto instrumento de medida das atitudes.

No entanto, algumas questões podem ser levantadas com relação a estes resultados. Uma das principais diferenças observadas é que, ao passo que o grupo de consumidores utiliza a pornografia com o objetivo de obter informações acerca da sexualidade, os não-consumidores percebem essas mesmas informações como prejudiciais ao desenvolvimento da sexualidade.

Podemos perceber também que se apresentou uma diferença significativa com relação ao gênero: os homens constituem $78 \%$ da amostra de consumidores, enquanto as mulheres correspondem a $70 \%$ da amostra de não-consumidores. Essa divergência pode ser analisada à luz da diferença da educação dada a homens e mulheres na nossa sociedade, ou seja, à diferença de gênero.

Em nossa sociedade, é exigido que homens e mulheres expressem sua sexualidade de maneiras diferenciadas, na tentativa de corresponder ao padrão estabelecido pelo meio. A negação do consumo de materiais pornográficos, por parte da amostra feminina, pode ser o resultado desta tentativa de agir da forma esperada, podendo ser considerado o primeiro viés desta pesquisa. Devido a este fato, em outras pesquisas serão aprofundados os estudos a respeito da relação entre este consumo e o sexismo, sendo sugerido que em estudos futuros, um instrumento de sexismo seja utilizado.

Algumas outras limitações deste estudo precisam ser citadas aqui. A impossibilidade da aplicação dos instrumentos em estudantes de instituições privadas de ensino superior restringiu de forma considerável a amostra retirada da população alvo da pesquisa. No entanto, deve ser observada a importância destes resultados, devida exatamente a essa lacuna existente no conhecimento acerca da sexualidade dos brasileiros e, principalmente, dos nordestinos.

Podemos perceber que, de acordo com os resultados analisados, ao lado dos aspectos tradicionalmente associados à pornografia (como o isolamento e a alienação), ela chega a ganhar, também e paradoxalmente, um caráter de positividade, a partir do momento em que seus consumidores buscam-na para aumentar suas fantasias e melhorar as relações sexuais com seus parceiros, exercendo, em circunstâncias específicas, um papel de estímulo ao prazer e ao contato mútuo.

A pornografia demonstra seu lado positivo a partir do momento em que seus consumidores a buscam para aumentar suas fantasias e melhorar as relações sexuais com seus parceiros, exercendo seu papel enquanto fonte de prazer e contato, muito mais do que de isolamento e alienação.

\section{Referências}

Anastasi, A., \& Urbina, S. (2000). Testagem psicológica. Porto Alegre, RS: ARTMED.

Baron, R., Byrne, D., \& Griffitt, W. (1974). Social psychology: understanding human interaction. Boston: Allyn \& Bacon.

Donnerstein, E., \& Linz, D. (1986) The question of pornography. Psychology Today, 20(12), 56-59.

Encyclopaedia Britannica. (1999). Verbete 'pornography'. Versão on-line, disponível na internet (http://www.britannica.com/bcom/eb/article/0/ 0,5716,62436+1+60885,00.html), obtida em janeiro de 2003.

Eysenck, H. (1976). Sexo, pornografia e personalidade: conseqüências sociais da psicologia moderna. São Paulo: Ibrasa.

Genuis, M., Violato, C., \& Paolucci, E. (1998). The effects of pornography on attitudes and behaviours in sexual and intimate relationships. Disponível on-line na internet. National Foundation for Family Research and Education, Calgary (http://www.nffre.org/html/documents/family_structure/ an_investigation_of_the_relationship.html). Obtida em janeiro de 2003.

Giddens, A. (1993). A transformação da intimidade: sexualidade, amor e erotismo nas sociedades modernas. São Paulo: Editora UNESP.

Gray, S. (1982). Exposure to pornography and aggression toward women: the case of the angry male. Social-Problems, 29(4), 387-398.

Krüger, H. (1986). Temas básicos de psicologia: introdução à psicologia social. São Paulo: EPU.

Kutchinsky, B. (1973). The effect of easy availability of pornography on the incidence of sex crimes: the Danish experience. Journal of Social Issues, 29, 163-181.

Lottes, I., Weinberg, M., \& Weller, I. (1993). Reactions to pornography on a college campus: for or against?. Sex Roles, 29, 69-89.

Middlebrook, P. (1980). Social psychology \& modern life. Nova York: Alfred Knopf. 
Pasquali, L. (1999). Instrumentos psicológicos: manual prático de elaboração. Brasília: LabPAM / IBAPP.

Pasquali, L, Souza, M., \& Tanizaki, T. (1985). Escala de atitude diante da sexualidade. Psicologia: Teoria e Pesquisa, 1(2), 175-194.

Super Interessante (1999). Especial Emoção e Inteligência. São Paulo: Editora Abril., Outubro.Pr@zer ou neur@?. Disponível on-line na internet (http:// www2.uol.com.br/super/emocao/1099/sexo.html); obtida em dezembro de 2002.
Suplicy, M. (1999). Conversando sobre sexo. Petrópolis, RJ: Vozes.

Thompson, M., Chaffee, S., \& Oshagan, H. (1990). Regulating pornography: a public dilemma. Journal of Communication, 40, 73-83.

Thornton, N. (1986). The politics of pornography: a critique of liberalism and radical feminism. Australian Journal of Sociology, 22, 25-45.

Zillmann, D., \& Bryant, J. (1982). Pornography, sexual callousness, and the trivialization of rape. Journal of Communication, 32(4), 10-21.

1 Extraído de estudo monográfico defendido para obtenção de título de Especialista em Sexualidade Humana pela Universidade Federal da Paraíba. Agradecimentos especiais a Universidade Federal da Paraíba e a todos os respondentes pela colaboração.

Valeschka Martins Guerra, mestre em Psicologia Social pela Universidade Federal da Paraíba, é doutoranda em Psicologia Cognitiva, pela Universidade Federal de Pernambuco. Endereço para correspondência: Rua Oneida Agra da Nóbrega , 141 - Altiplano; João Pessoa, PB; CEP 58046-200. Fone: (83) 9332-5650. E-mail: valeschka-guerra@uol.com.br

Fernando Cezar Bezerra de Andrade, doutorando em Educação pela Universidade Federal da Paraíba, é professor do Centro de Educação na Universidade Federal da Paraíba.

Mardonio Rique Dias, doutor em Psicologia Social pela Universidade de Brasília, é professor na Universidade Federal da Paraíba e coordenador do Grupo de Pesquisa (CNPq) Aspectos Psicossociais de Prevenção e da Saúde Coletiva. 